\section{Development of self-report assessment tool for anxiety among adolescents: Indonesian version of the Zung self-rating anxiety scale}

\author{
Anggi Setyowati, ${ }^{1,2}$ Min-Huey Chung,,3 \\ Ah. Yusuf ${ }^{4}$ \\ ${ }^{1}$ Faculty of Public Health, Universitas \\ Airlangga, Surabaya, Indonesia; ${ }^{2}$ School \\ of Nursing, College of Nursing, Taipei \\ Medical University, Taipei, Taiwan; \\ ${ }^{3}$ Department of Nursing, Taipei Medical \\ University-Shuang Ho Hospital, New \\ Taipei City, Taiwan; ${ }^{4}$ Department of \\ Psychiatric and Community Health \\ Nursing, Faculty of Nursing, Universitas \\ Airlangga, Surabaya, Indonesia
}

\begin{abstract}
Anxiety is common among adolescents. Self-report anxiety scales are needed to screen and prevent adolescents sinking into worse mental health. The purpose of this study was to assess the psychometric properties of Indonesia Zung Self-rating Anxiety Scale (SAS), including translation, validity, reliability and receiver operating characteristics (ROC). We used cross-sectional study and correlational design in this study. Total sample was 1,000 adolescents in junior and senior high school. The SAS was translated into Bahasa Indonesia based on World Health Organization guidelines. SAS and the Indonesia version of Beck Depression Inventori-(BDI) II questionnaires were used to develop construct validity. Correlation between item score and total score was used to establish convergent validity. Cronbach's alpha was used to calculate reliability and ROC curves were used to examine cut-off point of SAS. Construct validity showed positive correlation between the SAS and Indonesia version of BDI II scores. Convergent validity showed positive correlation between each item and total score. Cronbach's alpha 0.691 and the ROC 36.5. Thus, the Indonesia version of SAS provides a reliable and valid tool to screen anxiety among adolescents.
\end{abstract}

\section{Introduction}

Anxiety is common psychological problem among adolescents and is related to clinical concern. ${ }^{1}$ The prevalence of anxiety among adolescents is around $31 \%{ }^{2}$ and only $18 \%$ of adolescents with anxiety are in treatment. ${ }^{3}$ In Indonesia, $6 \%$ of adolescents, or 14 million people, had emotional disorder, with anxiety and depression symptoms. ${ }^{4}$

Anxiety has negative effects on physical and somatic symptoms, such as headache, fatigue, difficulty concentrating and also social phobia. ${ }^{5}$ Patients with anxiety are more likely to have physical symptoms rather than mental health problems5 and commonly also have depression. ${ }^{6}$ More than $25 \%$ of patients have anxiety and depression. ${ }^{6}$ Anxiety onset usually happens in adolescents. ${ }^{5}$ Primary care providers, adolescent's parents, should be aware of anxiety's symptoms. ${ }^{5}$ Unfortunately, they do not understand about anxiety.

A tool is needed to improve understanding and measure anxiety in adolescents, to be used in clinical and research for the purpose of rapid screening on a large scale to provide reliable data. ${ }^{7}$ Also required are public mental health efforts and strategies. ${ }^{8}$ The Zung Self-rating Anxiety Scale (SAS) is widely used to screen anxiety over the course of the past week, and the original SAS had good validity and reliability.7,9 The SAS has 20 items and is based on 20 items of diagnostic criteria, 15 being somatic symptoms and five affective symptoms. ${ }^{9}$ SAS has not been translated into Bahasa and, as far as we know, there is no study about the psychometrics of the SASIndonesia version. The aim of this study was to develop an Indonesian adaptation of the SAS and to validate reliability and cutoff points in a general population and a depression risk population.

\section{Materials and Methods}

This study used cross-sectional study and correlational design, using self-reported questionnaires. Data were collected from adolescents who studied at high school. The inclusion criteria were students in high school who both lived in a dormitory provided for students by the school and outside a dormitory. The exclusion criteria were students whose parents disagreed about their children participating in this survey or students who did not return the informed consent sheet. Total final sample was 1,000 adolescents.

Anxiety was measured by the Zung Self-Anxiety Scale (SAS) designed by William W. K. Zung. ${ }^{9}$ Each adolescent was assessed using the Indonesian version of scale. It is a 20 -item self-report assessment to measure anxiety levels and each question is scored on a Likert-type scale of 1-4. The total score on the SAS is from 20 to 80 , with
Correspondence: Min-Huey Chung, MinHuey Chung, School of Nursing, College of Nursing, Taipei Medical University No.250, Wu-Xing Street, Taipei, Taiwan, 110, R.O.C. Tel: 886-2-27361661-6317 -

Fax: 886-2-23772842.

E-mail: minhuey300@tmu.edu.tw

Key words: anxiety, psychometric, Indonesia, validity, reliability.

Acknowledgments: We would like to thank the teachers of the University for their friendly support.

Contributions: the authors contributed equally.

Conflict of interests: the authors declare no potential conflict of interests.

Funding: the work was supported by a TMU grant and Universitas Airlangga.

Clinical trials: the study is not involved any clinical trials.

Conference presentation: part of this paper was presented at the $3^{\text {rd }}$ International Symposium of Public Health, 2018 October 31 - November 1, Universitas Airlangga, Surabaya, Indonesia.

Dedication: the article is dedicated to School of Nursing, College of Nursing, Taipei Medical University No.250, Wu-Xing Street, Taipei, Taiwan.

Received for publication: 28 July 2019.

Revision received: 9 September 2019.

Accepted for publication: 15 October 2019.

This work is licensed under a Creative Commons Attribution NonCommercial 4.0 License (CC BY-NC 4.0).

(C) Copyright: the Author(s), 2019

Licensee PAGEPress, Italy

Journal of Public Health in Africa 2019; 10(s1):1172 doi:10.4081/jphia.2019.1172

higher scores indicating more anxiety. ${ }^{9}$ In this study, yje SAS-Indonesia version had a sufficient alpha coefficient (0.658). The BDI was created by Aaron T. Beck ${ }^{10}$ and each adolescent was assessed using the Indonesian version of the Beck Depression Inventory (BDI). The BDI is self-reporting tool to measure the presence and severity of depressive symptoms; patients with depression have anxiety disorders. ${ }^{6}$ The BDI has 21 items, each with a score $0-3$. The total score on the BDI is from 0 to 63 and the cutoff point of for the Indo BDI-II is 17. For validity, the BDI is closer to the diagnostic criteria for depression. 10 In this study, BDIII had a high alpha coefficient (0.815). 
Permission was granted by the ethics committee from Universitas Airlangga. Data were collected from August to September 2014. Permission to use SAS was granted from the original authors. We translated the original SAS into Bahasa based on World Health Organization guideward translation into Bahasa, the second step was expert panel, the aim of which was to review the result of translation, and the third step was back translation into English and comparison of the result with the original questionnaire. If the result was similar with the original questionnaire, the Bahasa questionnaire could be used. Furthermore, we conducted a pilot study to examine whether the questionnaire could be easily understood by adolescents and we then distributed the final version to adolescents.

All analyses were conducted using SPSS for Windows, $\mathrm{p}<0.05$ was considered statistically significant. Descriptive statistics were used to evaluate all variables. Internal consistency was used to measure the Cronbach's alpha for each item of the SAS. Convergent validity was calculated by examining the relationship between each item and total score using the Pearson product moment. Depression and anxiety may occur together; ${ }^{6}$ therefore, construct validity was developed to examine correlation between the score of the SAS and BDI-II. Using Pearson correlation, we hypothesized that adolescents with higher depression lines. ${ }^{11}$ As a first step, we conducted for- have higher score of anxiety. In addition, we used receiver operating characteristic (ROC) analysis to develop the cut-off point of the SAS among adolescents with or without anxiety.

\section{Results}

Table 1 shows the characteristics of respondents. The proportion of age was predominantly by participants aged 16-18 $(65.9 \%)$ and most participants were students in senior high school $(79.7 \%)$. In terms of residence, this was predominantly participants from West Indonesia (Java, Sumatra, and Kalimantan). The proportion of gender was almost equal, with female $58.9 \%$ and male $41.1 \%$.

\section{Reliability: Cronbach's alpha}

We examined internal consistency for the SAS-Indonesia version. Cronbach's alpha was 0.658 for 20 items and 0.691 for 19 items. Previous studies mentioned that Cronbach's alpha of $>0.5$ is considered acceptable. ${ }^{12,13}$

\section{Validity: convergent validity}

Convergent validity was measured by the relationship between each item and total score, one item is not significant (item 19). Table 2 shows the range of correlation between each domain was $\mathrm{r}=0.043$ $0.530, \mathrm{p}<0.05$.

\section{Construct validity}

Correlation between total score SAS and BDI-II was significant $(\mathrm{r}=0.394, \mathrm{p}<$ 0.05 ). This result supports our hypothesis that there is positive correlation between anxiety and depression. The mean of total score anxiety $($ mean $=39.14)$ in adolescents normal group is greater than adolescents in depression risk group $($ mean $=35.01)$ (Table 3).

\section{Cut-off point determination}

Receiver-operating characteristic (ROC) curves were used to measure cut-off point for the SAS-Indonesia version (Figure 1). The area below the ROC curve was

Table 1. Demographic characteristics of respondents $($ Total sample $=1000)$.

\begin{tabular}{lcc} 
Characteristics & n & $\%$ \\
Age & & \\
$13-15$ & 341 & 34.1 \\
$16-18$ & 659 & 65.9 \\
$\quad$ Mean $=15.9$ SD $=1.2$ & & \\
Gender & & \\
$\quad$ Female & 589 & 58.9 \\
$\quad$ Male & 411 & 41.1 \\
\hline Class & & \\
$\quad$ Junior High School & 203 & 20.3 \\
$\quad$ Senior High School & 797 & 79.7 \\
Residence & & \\
$\quad$ West of Indonesia & 938 & 93.8 \\
$\quad$ Centre of Indonesia & 59 & 5.9 \\
$\quad$ East of Indonesia & 3 & 0.3 \\
\end{tabular}

Table 2. Item total correlation of SAS $(\mathrm{n}=1000)$.

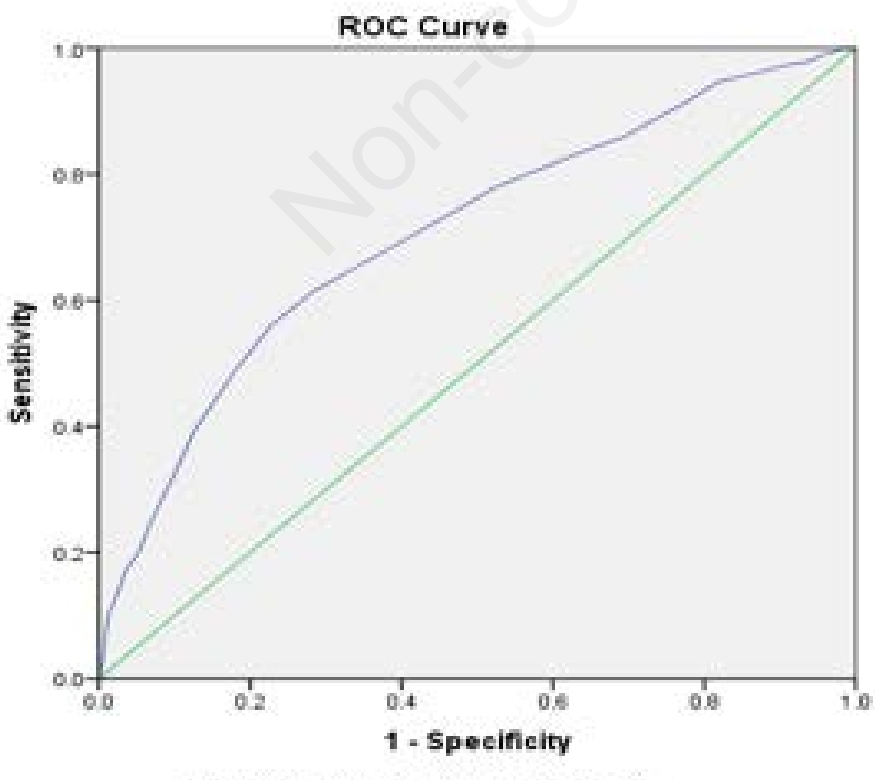

Diagenal segments are produced by ties

Figure 1. Note: Area below the ROC curve: 0.706; standard error: 0.017; asymptotic sig. $<0.001$; lower bound: 0.674; and upper bound: 0.739 .

\begin{tabular}{lll} 
Item & Item-total correlation p-value \\
SAS 1 & 0.444 & $<0.05$ \\
SAS 2 & 0.451 & $<0.05$ \\
\hline SAS 3 & 0.501 & $<0.05$ \\
SAS 4 & 0.424 & $<0.05$ \\
\hline SAS 5 & 0.311 & $<0.05$ \\
SAS 6 & 0.455 & $<0.05$ \\
\hline SAS 7 & 0.524 & $<0.05$ \\
SAS 8 & 0.516 & $<0.05$ \\
\hline SAS 9 & 0.303 & $<0.05$ \\
SAS 10 & 0.486 & $<0.05$ \\
\hline SAS 11 & 0.530 & $<0.05$ \\
SAS 12 & 0.324 & $<0.05$ \\
\hline SAS 13 & 0.311 & $<0.05$ \\
SAS 14 & 0.411 & $<0.05$ \\
\hline SAS 15 & 0.453 & $<0.05$ \\
SAS 16 & 0.276 & $<0.05$ \\
\hline SAS 17 & 0.180 & $<0.05$ \\
SAS 18 & 0.252 & $<0.05$ \\
\hline SAS 19 & 0.043 & $>0.05$ \\
SAS 20 & 0.341 & $<0.05$ \\
\hline & &
\end{tabular}


0.706, which means that the SAS-Indonesia version would be considered to be "acceptable" at differentiating adolescents with or without anxiety. The result showed that 36.5 was the global score of the SAS-Indonesia version and represented the best sensitivity and specificity for measuring anxiety among adolescents with or without depression (Table 4).

\section{Discussion}

The aim of this study was to develop an Indonesian adaptation of the SAS and to validate reliability and cut-off point among Indonesian adolescents. This study was consistent with previous study. ${ }^{7}$ Our finding showed that the SAS-Indonesia version had good validity and reliability and can be used to screen anxiety. The construct validity of the SAS-Indonesia version was acceptable with the Indo BDI-II. This finding was consistent with suggestions that anxiety is associated with depression. ${ }^{14}$ Most people with depression, also have an anxiety problem. ${ }^{6}$

Convergent validity of the SAS Indonesia version was satisfactory, the positive correlation between each item and total score was more than $0.2,{ }^{15}$ except item number 19 about sleep. We assumed that adolescents are unaware of sleep problems, since adolescents commonly have sleep problems and change in their sleep-wake patterns. ${ }^{16} \mathrm{We}$ still consider to use this item, and calculate internal consistency and cutoff point with 20 items. Previous study mentioned that psychological factors, such as depression and anxiety, were associated with poor sleep quality. ${ }^{17,18}$

We tested internal consistency for the SAS Indonesia version. Cronbach's alpha for SAS-I was 0.658 for 20 items. It showed that the SAS Indonesia version has good internal consistency and is acceptable. The mean total score of the SAS Indonesia version indicates that adolescents in depression risk group were higher than the adolescents normal group. It supported that the SAS Indonesia version can be used to screen anxiety among healthy adolescents and those with depression.

Receiver operating characteristic curve analyses showed that the cut-off mean value was 36 . This study was not similar with previous study in Chinese populations, in which the cut-off point showed anxiety symptoms to be more than $40 .{ }^{19}$ Our study had lower mean than previous study to assess anxiety among Indonesian adolescents. Our finding suggests that, if adolescents had total score of more than 36, they may have an anxiety problem. The results must be interpreted cautiously based on cul- tural differences in each country. ${ }^{20}$

There are several limitations in this study such as we did not perform factor analysis. Further study is needed to calcu- late exploratory factor analysis to determine subscale categories in items of SAS. Also, it is important to develop the psychometric of the SAS-Indonesia version using anxiety

Table 3. Mean difference between adolescents normal group and adolescent depression risk group.

\begin{tabular}{cccccc} 
& \multicolumn{2}{c}{$\begin{array}{c}\text { Adolescents } \\
\text { normal group }\end{array}$} & \multicolumn{2}{c}{$\begin{array}{c}\text { Adolescents } \\
\text { depression }\end{array}$} & Correlation \\
& Mean & SD & Mean & SD & \\
Total Score SAS & 35.01 & 5.13 & 39.14 & 5.82 & $0.394^{* *}$ \\
\hline
\end{tabular}

${ }^{*}$ p value $<0.05$, SD: Standard Deviation

Table 4. Sensitivity and specificity of the SAS-Indonesia version score using ROC curve analysis.

\begin{tabular}{|c|c|c|c|c|}
\hline Global & Sensitivity & 1 - specificity & Specificity & Sensitivity + specificity \\
\hline 18.0000 & 1.000 & 1.000 & 0.000 & 1.000 \\
\hline 20.0000 & 1.000 & 0.998 & 0.002 & 1.002 \\
\hline 21.5000 & 1.000 & 0.996 & 0.004 & 1.004 \\
\hline 22.5000 & 1.000 & 0.995 & 0.005 & 1.005 \\
\hline 23.5000 & 1.000 & 0.987 & 0.013 & 1.013 \\
\hline 24.5000 & 0.998 & 0.978 & 0.022 & 1.02 \\
\hline 25.5000 & 0.993 & 0.969 & 0.031 & 1.024 \\
\hline 26.5000 & 0.989 & 0.956 & 0.044 & 1.033 \\
\hline 27.5000 & 0.978 & 0.936 & 0.064 & 1.042 \\
\hline 28.5000 & 0.973 & 0.911 & 0.089 & 1.062 \\
\hline 29.5000 & 0.958 & 0.858 & 0.142 & 1.100 \\
\hline 30.5000 & 0.947 & 0.818 & 0.182 & 1.129 \\
\hline 31.5000 & 0.911 & 0.771 & 0.229 & 1.140 \\
\hline 32.5000 & 0.858 & 0.691 & 0.309 & 1.167 \\
\hline 33.5000 & 0.831 & 0.629 & 0.371 & 1.202 \\
\hline 34.5000 & 0.778 & 0.522 & 0.478 & 1.256 \\
\hline 35.5000 & 0.738 & 0.465 & 0.535 & 1.273 \\
\hline 36.5000 & 0.682 & 0.384 & 0.616 & 1.298 \\
\hline 37.5000 & 0.616 & 0.285 & 0.715 & 1.367 \\
\hline 38.5000 & 0.560 & 0.227 & 0.773 & 1.333 \\
\hline 39.5000 & 0.482 & 0.176 & 0.824 & 1.306 \\
\hline 40.5000 & 0.391 & 0.125 & 0.875 & 1.266 \\
\hline 41.5000 & 0.311 & 0.095 & 0.905 & 1.216 \\
\hline 42.5000 & 0.240 & 0.065 & 0.935 & 1.175 \\
\hline 43.5000 & 0.204 & 0.055 & 0.945 & 1.149 \\
\hline 44.5000 & 0.169 & 0.035 & 0.965 & 1.134 \\
\hline 45.5000 & 0.138 & 0.025 & 0.975 & 1.113 \\
\hline 46.5000 & 0.102 & 0.013 & 0.987 & 1.089 \\
\hline 47.5000 & 0.073 & 0.009 & 0.991 & 1.064 \\
\hline 48.5000 & 0.060 & 0.007 & 0.993 & 1.053 \\
\hline 49.5000 & 0.047 & 0.007 & 0.993 & 1.040 \\
\hline 50.5000 & 0.031 & 0.005 & 0.995 & 1.026 \\
\hline 51.5000 & 0.024 & 0.005 & 0.995 & 1.019 \\
\hline 52.5000 & 0.020 & 0.004 & 0.996 & 1.016 \\
\hline 53.5000 & 0.011 & 0.002 & 0.998 & 1.009 \\
\hline 55.5000 & 0.007 & 0.002 & 0.998 & 1.005 \\
\hline 58.0000 & 0.004 & 0.002 & 0.998 & 1.002 \\
\hline 59.5000 & 0.000 & 0.002 & 0.998 & 0.998 \\
\hline 61.0000 & 0.000 & 0.000 & 1.000 & 1.000 \\
\hline
\end{tabular}


diagnosis in clinical population. Despite the limitations, the results of this study support the reliability, convergent validity, and construct validity of the SAS-Indonesia version to screen anxiety among adolescents.

\section{Conclusions}

The results of this study support the reliability and validity of the Indonesia version of SAS to screen anxiety among adolescents. It can be used to quickly assess anxiety problems for primary healthcare providers, adolescents' parents, as well as adolescents themselves.

\section{References}

1. Segal DL, June A, Payne M, et al. Development and initial validation of a self-report assessment tool for anxiety among older adults: the Geriatric Anxiety Scale. Journal of Anxiety Disorders 2010;24(7):709-14.

2. Merikangas KR, He J-p, Burstein M, et al. Lifetime prevalence of mental disorders in US adolescents: results from the National Comorbidity Survey Replication-Adolescent Supplement (NCS-A). Journal of the American Academy of Child \& Adolescent Psychiatry 2010;49(10):980-9.

3. Merikangas KR, He J-p, Burstein M, et al. Service utilization for lifetime mental disorders in US adolescents: results of the National Comorbidity SurveyAdolescent Supplement (NCS-A). Journal of the American Academy of Child \& Adolescent Psychiatry 2011;50(1):32-45.
4. Kementerian Kesehatan Republik Indonesia. Family support for Public Mental Health 2016. Available from: http:/www.depkes.go.id/article/print/1 6100700005/peran-keluarga-dukungkesehatan-jiwa-masyarakat.html. Accessed on: 6 October 2019.

5. Siegel RS, Dickstein DP. Anxiety in adolescents: Update on its diagnosis and treatment for primary care providers. Adolescent Health, Medicine and Therapeutics 2012;3:1.

6. Tiller JW. Depression and anxiety. The Medical Journal of Australia 2013; 199(6):28-31.

7. Ramirez SZ, Lukenbill J. Psychometric properties of the Zung Self-Rating Anxiety Scale for adults with intellectual disabilities (SAS-ID). Journal of Developmental and Physical Disabilities 2008;20(6):573-80.

8. Abdulmalik JO, Sale S. Pathways to psychiatric care for children and adolescents at a tertiary facility in northern Nigeria. Journal of Public Health in Africa 2012;3(1).

9. Zung WW. A rating instrument for anxiety disorders. Psychosomatics: Journal of Consultation and Liaison Psychiatry 1971;12(6):371-9.

10. Beck AT, Steer RA, Brown GK. Beck depression inventory-II. San Antonio: Psychological Corporation; 1996.

11. World Health Organization. Process of translation and adaptation of instruments 2014 [Available from: http://www.who.int/substance abuse/re search tools/translation/en/. Accessed on: 10 May 2018.

12. Morera OF, Stokes SM. Coefficient $\alpha$ as a measure of test score reliability: Review of 3 popular misconceptions.
American Journal of Public Health 2016;106(3):458-61.

13. Streiner DL. Starting at the beginning: an introduction to coefficient alpha and internal consistency. Journal of Personality Assessment 2003;80(1):99103.

14. Muntingh $\mathrm{AD}$, van der Feltz-Cornelis $\mathrm{CM}$, van Marwijk HW, et al. Is the beck anxiety inventory a good tool to assess the severity of anxiety? A primary care study in The Netherlands study of depression and anxiety (NESDA). BMC Family Practice 2011;12(1):66.

15. Kline P. A handbook of test construction: Introduction to psychometric design. New York: Methuen; 1986.

16. Crowley SJ, Van Reen E, LeBourgeois $\mathrm{MK}$, et al. A longitudinal assessment of sleep timing, circadian phase, and phase angle of entrainment across human adolescence. PloS one 2014;9(11):e112199.

17. Tsai YL, Chen CW, Cheng HC, et al. Cognitive and behavioral factors in insomnia comorbid with depression and anxiety. Sleep and Biological Rhythms 2013;11(4):237-44.

18. Lund HG, Reider BD, Whiting AB, et al. Sleep patterns and predictors of disturbed sleep in a large population of college students. Journal of Adolescent Health 2010;46(2):124-32.

19. Gao Y-Q, Pan B-C, Sun W, et al. Anxiety symptoms among Chinese nurses and the associated factors: a cross sectional study. BMC Psychiatry 2012;12(1):141.

20. Chang HJ, Lin CC, Chou KR, et al. Chinese version of the positive and negative suicide ideation: instrument development. Journal of Advanced Nursing 2009;65(7):1485-96. 